\title{
PEMANFAATAN PELAYANAN KESEHATAN PADA LANSIA DI WILAYAH KERJA PUSKESMAS TILONGKABILA
}

\author{
Sylva Flora Ninta Tarigan \\ Fakultas Olahraga Dan Kesehatan Universitas Negeri Gorontalo \\ E-mail: floraninta@gmail.com
}

\begin{abstract}
ABSTRAK
Faktor degenaratif (penuaan) dapat berdampak pada berbagai aspek kehidupan, baik aspek sosial, ekonomi, maupun kesehatan. Data Dinas Kesehatan Kabupaten Bone Bolango tahun 2017 menunjukkan bahwa 89,6\% lansia tidak memanfaatkan pelayanan kesehatan. Penelitian ini bertujuan untuk menganalisis pemanfaatan pelayanan kesehatan pada lansia di wilayah kerja Kecamatan Tilongkabila ditinjau dari tingkat pengetahuan. Jenis penelitian yang digunakan adalah survey analitik dengan rancangan cross sectional untuk menganalisis hubungan antara tingkat pengetahuan dengan pemanfaatan pelayanan kesehatan pada lansia di wilayah kerja Kecamatan Tilongkabila. Populasi dalam penelitian ini adalah seluruh lansia yang berumur $>50$ tahun yang mendapatkan pelayanan kesehatan di 4 desa dengan jumlah 1.190 orang. Sampel diperoleh sebanyak 299 orang yang diambil menggunakan teknik stratified random sampling. Data dikumpulkan melalui wawancara dengan menggunakan kuesioner. Analisis data menggunakan uji korelasi spearman rank. Hasil penelitian menunjukan bahwa ada hubungan antara tingkat pengetahuan lansia dengan pemanfaatan pelayanan kesehatan $(\mathrm{p}=0,001)$, artinya pengetahuan sudah baik, namun masih ada yang belum mengikuti pelayanan kesehatan karena faktor jarak rumah. Diharapkan bagi petugas kesehatan lebih meningkatkan pengetahuan lansia melalui optimalisasi posyandu lansia.
\end{abstract}

Kata Kunci : Tingkat pengetahuan lansia, pemanfaatan pelayanan kesehatan.

\begin{abstract}
Degenerative factors (aging) can have an impact on various aspects of life, both social, economic and health aspects. Data from Bone Bolango Health Office in 2017 shows that $89.6 \%$ of elderly people do not use health services. This study aims to analyze the utilization of health services in the elderly in the work area of Tilongkabila Subdistrict in terms of level of knowledge. The type of research used is an analytical survey with a cross sectional design to analyze the relationship between the level of knowledge and the utilization of health services in the elderly in the Tilongkabila District work area. The population in this study were all elderly >50 years old who received health services in 4 villages with a total of 1,190 people. Samples were obtained as many as 299 people taken using stratified random sampling technique. Data was collected through interviews using a questionnaire. Data analysis used Spearman rank correlation test. The results showed that there was a relationship between the level of knowledge of the elderly with the use of health services $(p=0.001)$, meaning that knowledge was good, but there were still those who had not attended health services because of the distance factor of the house. It is expected that health workers will increase the knowledge of the elderly through optimizing the elderly Posyandu.
\end{abstract}

Keywords: Level of knowledge of the elderly, utilization of health services. 
PENDAHULUAN

Jumlah lansia di Indonesia mencapai 20,24 juta jiwa atau setara dengan 8,03\% dari seluruh penduduk Indonesia tahun 2014. Jumlah lansia perempuan lebih besar 10,77 juta dibandingkan laki-laki 9,47 juta. Lansia yang tinggal di perdesaan sebanyak 10,87 juta jiwa, lebih banyak daripada lansia yang tinggal di perkotaan sebanyak 9,37 juta jiwa (Susenas, 2014).

Proses penuaan penduduk berdampak pada berbagai aspek kehidupan, baik sosial, ekonomi, dan terutama kesehatan. Semakin bertambahnya usia, fungsi organ tubuh akan semakin menurun, karena faktor alamiah maupun karena penyakit. Dengan demikian, peningkatan jumlah penduduk lanjut usia menjadi salah satu indikator keberhasilan pembangunan kesehatan (Maryam, 2011).

Pembangunan kesehatan berkembang dengan cepat dan menyentuh seluruh segi kehidupan sehingga perlu disusun tatanan upaya kesehatan. Upaya kesehatan yang dimaksud adalah dalam bentuk pelayanan dasar Puskesmas, peran serta masyarakat dan rujukan kesehatan (Depkes RI, 2004).

Berdasarkan data Dinas kesehatan Kabupaten Bone Bolango tahun 2017, jumlah penduduk lansia sebesar 192.946, jumlah kelompok umur 45 tahun ke atas sebanyak 118.608, jumlah lansia umur 60 tahun ke atas sebanyak 66.237, dan jumlah lansia umur 70 tahun sebanyak 8101 jiwa. Di wilayah kerja Puskesmas Tilongkabila terdapat 7 desa, dengan jumlah penduduk lansia sebanyak 1.664 orang.
Dalam pelayanan kesehatan yang terdaftar 818 lansia sedangkan yang aktif hanya 85 lansia. Pelayanan kepada para lansia ini dilakukan melalui beberapa program, diantaranya pelayanan posyandu lansia, prolanis, dan home care. Pelayanan kesehatan dilakukan secara gratis akan tetapi masih ada juga lansia yang tidak mau ikut pelayanan tersebut, sehingga petugas mengunjungi rumah para lansia namun masih juga terkendala karena ada menolak kunjungan tersebut.

Dari hasil observasi awal pada wilayah puskesmas Tilongkabila yang mengikuti pelayanan kesehatan lansia hanya 85 lansia dari 818 lansia. Sedangkan dari hasil wawancara dari beberapa lansia bahwa pelayanan kesehatan lansia itu hanya tempat berobat orang sakit, hal ini menandakan bahwa tingkat pengetahuan masih rendah, dan masih banyak lansia yang tidak mengikuti pelayanan kesehatan lansia di karenakan mereka sibuk dengan aktivitas masing-masing seperti ada yang pergi ke kebun dan ada yang tidak paham tentang pemanfaatan pelayanan kesehatan lansia dan tidak mengetahui manfaat yang sesungguhnya.

Berdasarkan uraian masalah di atas maka perlu untuk dilakukan penelitian tentang pemanfaatan pelayanan kesehatan pada lansia di wilayah kerja Puskesmas Tilongkabila.

\section{METODE PENELITIAN}

\section{a. Lokasi dan Waktu Penelitian}

Penelitian ini dilaksanakan pada bulan Agustus 2017 yakni di Wilayah kerja Puskesmas Tilongkabila Kabupaten Bonebolango. 


\section{b. Desain Penelitian}

Jenis penelitian yang digunakan adalah survey analitik dengan rancangan cross sectional untuk menganalisis hubungan antara tingkat pengetahuan dengan pemanfaatan pelayanan kesehatan pada lansia di wilayah kerja Kecamatan Tilongkabila.

\section{c. Populasi Dan Sampel}

Populasi dalam penelitian ini adalah seluruh lansia yang berumur 50 tahun ke atas yang mendapatkan pelayanan kesehatan di 4 desa dengan jumlah 1.190 Orang. Sedangkan sampel diperoleh sebanyak 299 orang yang didapat menggunakan teknik stratified random sampling yakni teknik yang digunakan bila populasi mempunyai anggota/unsur yang tidak homogen dan berstrata secara proporsional.

\section{HASIL DAN PEMBAHASAN}

\section{a. Hasil Penelitian}

Tabel 3.1 Distribusi Responden

Berdasarkan Kelompok Umur

\begin{tabular}{cccc}
\hline No & $\begin{array}{c}\text { Jenis } \\
\text { Kelamin }\end{array}$ & $\mathrm{n}$ & $\%$ \\
\hline 1 & Laki-Laki & 106 & 35,45 \\
\hline 2 & Perempuan & 193 & 64,55 \\
\hline & Total & 299 & 100,00 \\
\hline
\end{tabular}

Sumber: Data primer, 2017

Tabel 3.1 menunjukkan bahwa paling banyak responden pada kelompok umur 56 65 Tahun yaitu sebanyak 104 orang $(34,78 \%)$.
Tabel 3.2 Distribusi Responden

Berdasarkan Jenis Kelamin

\begin{tabular}{|c|c|c|c|}
\hline No & $\begin{array}{c}\text { Kelompok } \\
\text { Umur (Tahun) }\end{array}$ & $\mathrm{n}$ & $\%$ \\
\hline 1 & $46-55$ & 100 & 33,44 \\
\hline 2 & $56-65$ & 104 & 34,78 \\
\hline 3 & $66-75$ & 95 & 31,77 \\
\hline \multicolumn{2}{|c|}{ Total } & 299 & 100,00 \\
\hline
\end{tabular}

Sumber: Data primer, 2017

Tabel 3.2 menunjukkan bahwa paling banyak responden berjenis kelamin perempuan yaitu 193 orang $(64,55 \%)$.

Tabel 3.3 Distribusi Responden Berdasarkan Pendidikan

\begin{tabular}{|c|c|c|c|}
\hline No & Pendidikan & $\mathrm{n}$ & $\%$ \\
\hline 1 & $\begin{array}{c}\text { Tidak } \\
\text { Tamat SD }\end{array}$ & 18 & 6,02 \\
\hline 2 & $\begin{array}{c}\text { Tamat SD/ } \\
\text { Sederajat }\end{array}$ & 246 & 82,27 \\
\hline 3 & $\begin{array}{c}\text { Tamat } \\
\text { SMP/ } \\
\text { Sederajat }\end{array}$ & 21 & 7,02 \\
\hline 4 & $\begin{array}{l}\text { Tamat } \\
\text { SMA/ } \\
\text { Sederajat }\end{array}$ & 12 & 4,01 \\
\hline 5 & $\mathrm{PT}$ & 2 & 0,67 \\
\hline & Total & 299 & 100,00 \\
\hline
\end{tabular}

Sumber: Data primer, 2017

Tabel 3.3 menunjukkan bahwa paling banyak responden dengan latar belakang pendidikan tamatan SD/sederajat yakni 246 orang $(82,27 \%)$. 
Tabel 3.4 Distribusi Responden Berdasarkan Pekerjaan

\begin{tabular}{cccc}
\hline No & Pekerjaan & $\mathrm{n}$ & $\%$ \\
\hline 1 & $\begin{array}{c}\text { Tidak } \\
\text { Bekerja }\end{array}$ & 7 & 2,34 \\
\hline 2 & URT & 186 & 62,21 \\
\hline 3 & Buruh & 2 & 0,67 \\
\hline 4 & Petani & 71 & 23,75 \\
\hline 5 & $\begin{array}{c}\text { fukang } \\
\text { Jahit }\end{array}$ & 2 & 0,67 \\
\hline 6 & $\begin{array}{c}\text { Tukang } \\
\text { Kayu }\end{array}$ & 6 & 2,01 \\
\hline 7 & Pedagang & 11 & 3,68 \\
\hline 8 & $\begin{array}{c}\text { Aparat } \\
\text { Desa }\end{array}$ & 1 & 0,33 \\
\hline 9 & Wiraswasta & 11 & 3,68 \\
\hline 10 & $\begin{array}{c}\text { Pensiunan } \\
\text { Guru }\end{array}$ & 2 & 0,67 \\
\hline & Total & 299 & 100,00 \\
\hline Sumber: Dataprimer & 2017 &
\end{tabular}

Sumber: Data primer, 2017

Tabel 3.4 menunjukkan bahwa paling banyak responden dengan pekerjaan URT yakni sebanyak 186 orang $(62,21 \%)$.
Tabel 3.5 Distribusi Responden

Berdasarkan Pengetahuan

\begin{tabular}{cccc}
\hline No & Pengetahuan & $\mathrm{n}$ & $\%$ \\
\hline 1 & Baik & 167 & 55,85 \\
\hline 2 & Cukup & 89 & 29,77 \\
\hline 3 & Kurang & 43 & 14,38 \\
\hline & Total & 299 & 100,00
\end{tabular}

Sumber: Data primer, 2017

Tabel 3.5 menunjukkan bahwa paling banyak responden dengan tingkat pengetahuan baik yaitu sebanyak 167 orang $(55,85 \%)$.

Tabel 3.6 Distribusi Responden

\section{Berdasarkan Pemanfaatan}

Pelayanan Kesehatan

\begin{tabular}{cccc} 
No & $\begin{array}{c}\text { Pemanfaatan } \\
\text { Pelayanan }\end{array}$ & $\mathrm{n}$ & $\%$ \\
\hline & & & \\
\hline 1 & Memanfaatkan & 266 & 88,96 \\
\hline 2 & $\begin{array}{c}\text { Tidak } \\
\text { Memanfaatkan }\end{array}$ & 33 & 11,04 \\
\hline & Total & 299 & 100,00
\end{tabular}

Sumber: Data primer, 2017

Tabel 3.6 menunjukkan bahwa paling banyak responden memanfaatkan pelayanan kesehatan yakni sebanyak 266 orang $(88,96 \%)$.

Tabel 3.7 Hubungan antara Pengetahuan Lansia dengan Pemanfaatan Pelayanan Kesehatan di Wilayah Kerja Puskesmas Tilongkabila Kabupaten Bone Bolango

\begin{tabular}{ccccc}
\hline \multirow{2}{*}{ Pengeta-huan } & \multicolumn{2}{c}{ Pemanfaatan Pelayanan } & \multirow{2}{*}{ Total } & p-Value \\
\cline { 2 - 4 } & Ya & Tidak & & \\
\hline Baik & 155 & 12 & 167 & 0,001 \\
\hline Cukup & 78 & 11 & 89 & \\
\hline Kurang & 33 & 10 & 43 & \\
\hline Jumlah & 266 & 33 & 299 & \\
\hline
\end{tabular}

Sumber: Data primer, 2017

Tabel 3.7 menunjukkan bahwa berdasarkan hasil analisis diperoleh nilai $p$ value 0,001 , artinya terdapat hubungan yang signifikan antara pengetahuan lansia dengan pemanfaatan pelayanan kesehatan pada lansia
Di Wilayah Kerja Puskesmas Tilongkabila Kabupaten Bone Bolango. 


\section{Pembahasan}

Responden yang memanfaatkan dan tidak memanfaatkan pelayanan kesehatan yang paling banyak yaitu pada tingkat pengetahuan baik. Hal ini disebabkan karena adanya perbedaan tingkat pengetahuan, yang dapat mempengaruhi seseorang untuk melakukan hal-hal yang baik. Pengetahuan adalah hasil penginderaan manusia, atau hasil tahu seseorang terhadap obyek melalui indera yang dimilikinya(mata, hidung, telinga, dan sebagainya) (Notoatmodjo,2005).

Hasil penelitian ini sejalan dengan penelitian yang dilakukan oleh Sari (2013) di Desa Karang Jati Kalijambe Sergan yakni ada hubungan pengetahuan lanjut usia terhadap pemanfaatan posyandu lanjut usia disebabkan oleh kurangnya kunjungan ke posyandu. Dari hasil penelitiannya bahwa lansia yang memiliki pengetahuan baik untuk datang ke posyandu lansia sebanyak 5 kali dibandingkan dengan lansia yang memiliki pengetahuan tidak baik. Penelitian lain yang dilakukan oleh Zakir (2012) di Wilayah Kerja Puskesmas Sukabumi Bandar Lampung, diperoleh hubungan yang bermakna antara pengetahuan dengan pemanfaatan posyandu kencana $(\mathrm{p}=0.025)$.

Pengetahuan lansia yang baik ini didapatkan dari adanya penyuluhan yang di dokumentasikan berbagai kegiatan pelayanan kesehatan pada lansia dan paparan informasi mengenai pelayanan kesehatan sehingga lanjut usia paham dengan keberadaan pelayanan kesehatan lansia. Oleh karena itu informasi sangat mendukung sekali dalam meningkatkan pengetahuan seseorang. Hal ini diperkuat oleh Wawan \& Dewi (2010), bahwa penyuluhan kesehatan dapat meningkatkan pengalaman seseorang dibandingkan dengan yang tidak diberi penyuluhan, pendidikan kesehatan dan peningkatan pengetahuan dapat meningkatkan perilaku kesehatan.

Responden yang berpengetahuan baik tapi tidak memanfaatkan pelayanan kesehatan dapat dipengaruhi oleh faktor lain misalnya jarak rumah yang jauh dari pelayanan kesehatan. Bagi responden yang pengetahuan cukup tapi dapat memanfaatkan pelayanan kesehatan dipengaruhi oleh faktor pendidikan dan pekerjaan. Hal ini menunjukkan bahwa dia tahu mengaplikasikan apa yang telah dipelajarinya dan di dapatkan dari penyuluhan kesehatan, dan mereka masih sempat meluangkan waktu untuk memanfaatkan pelayanan kesehatan. Disamping itu masih terdapat responden yang memiliki pengetahuan kurang, yang dapat memanfaatkan pelayanan tersebut ini dapat disebabkan oleh lingkungan, dimana pemanfaatan pelayanan kesehatan lansia yang baik membuat responden ingin mengikutinya.

Pengetahuan lansia yang kurang tentang pelayanan kesehatan lansia (Posyandu lansia, prolanis dan home care) dapat mengakibatkan kurangnya pemahaman dan pengalaman lansia dalam pemanfaatan pelayanan ksehatan tersebut. Keterbatasan pengetahuan ini akan mengakibatkan dampak yang kurang baik dalam pemeliharaan kesehatannya. Dengan menghadiri kegiatan posyandu, lansia akan mendapatkan penyuluhan tentang bagaimana cara hidup dengan segala keterbatasan atau 
masalah kesehatan yang melekat pada

mereka. Dengan pengalaman ini, pengetahuan lansia menjadi meningkat, yang menjadi dasar pembentukan sikap dan dapat mendorong minat atau motivasi mereka untuk selalu mengikuti kegiatan posyandu lansia (Sulistyorini dkk, 2010).

\section{SIMPULAN DAN SARAN}

\section{a. Simpulan}

Berdasarkan hasil penelitian dapat disimpulkan bahwa ada hubungan antara pengetahuan lansia dengan pelayanan kesehatan dengan $p$-value $=0,001<0,05 \mathrm{Ha}$ ini karena pengetahuan sudah baik, akan tetapi masih ada yang belum mengikuti pelayanan kesehatan yang di pengaruhi oleh jarak rumah.

\section{b. Saran}

Diharapkan bagi petugas kesehatan lebih meningkatkan pengetahuan, kesadaran lansia dan penyuluhan tentang manfaat pelayanan kesehatan seperti posyandu lansia.

\section{REFERENSI}

Depkes RI. 2004. Keputusan Menteri Kesehatan RI Nomor
128/MENKES/SK/II/2004 ttg Kebijakan Dasar Pusat Kesehatan Masyarakat. Jakarta

Maryam,et al. (2011). Mengenal Usia Lanjut dan Perawatannya. Jakarta: Salemba Medika.

Notoatmodjo. 2005. Pendidikan dan Perilaku Kesehatan. Jakarta : Rineka Cipta

Sari. 2013. Pengaruh Tingkat Pengetahuan Lanjut Usia Terhadap Pemanfaatan Posyandu Lanjut Usia di Desa Karangjati Kalijambe Sragen Tahun 2013. Skripsi.Jawa Tengah: Fakultas Kesehatan. Universitas Muhammadiyah Surakarta

Sulistyorini, I.,C, Pebriyanti, S. dan Proverawati, A. 2010. Posyandu dan Desa Siaga.yogyakarta: Nuha Medika.

Susenas 2014, Badan Pusat Statistik RI

Wawan, A dan M, Dewi. 2010. Teori Dan Pengukuran Pengetahuan, Sikap, Dan Perilaku Manusia. Yogyakarta: Nuha Med 
